\title{
EXTREME WAVE PRESSURES AND LOADS ON A PILE-SUPPORTED WHARF DECK - INFLUENCES OF AIR GAP AND WAVE DIRECTION
}

\author{
Andrew Cornett, National Research Council Canada, Andrew.Cornett@nrc-cnrc.gc.ca
}

\begin{abstract}
INTRODUCTION
Many deck-on-pile structures are located in shallow water depths at elevations low enough to be inundated by large waves during intense storms or tsunami. Many researchers have studied wave-in-deck loads over the past decade using a variety of theoretical, experimental, and numerical methods. Wave-in-deck loads on various pile supported coastal structures such as jetties, piers, wharves and bridges have been studied by Tirindelli et al. (2003), Cuomo et al. (2007, 2009), Murali et al. (2009), and Meng et al. (2010). All these authors analyzed data from scale model tests to investigate the pressures and loads on beam and deck elements subject to wave impact under various conditions. Wavein-deck loads on fixed offshore structures have been studied by Murray et al. (1997), Finnigan et al. (1997), Bea et al. (1999, 2001), Baarholm et al. (2004, 2009), and Raaij et al. (2007). These authors have studied both simplified and realistic deck structures using a mixture of theoretical analysis and model tests. Other researchers, including Kendon et al. (2010), Schellin et al. (2009), Lande et al. (2011) and Wemmenhove et al. (2011) have demonstrated that various CFD methods can be used to simulate the interaction of extreme waves with both simple and more realistic deck structures, and predict wave-in-deck pressures and loads.
\end{abstract}

Despite considerable previous research, establishing reliable estimates of extreme hydrodynamic pressures and forces on low elevation deck structures for use in design remains challenging due to the complex and somewhat chaotic nature of the wave interactions that occur. In this paper, new results from an extensive set of $3 \mathrm{D}$ scale model tests conducted to support the design of a large free-standing pile-supported wharf (or pier) are presented. The important influences of deck clearance (or air gap) and wave direction on the extreme pressures and loads exerted on the deck slab and horizontal support beams will be explored and discussed.

\section{LABORATORY EXPERIMENTS}

Experiments were conducted in which a detailed 1:35 scale model of the outer portion of the wharf structure, the mooring and berthing dolphins, and the surrounding bathymetry was set up in a $63 \mathrm{~m} \times 14 \mathrm{~m}$ wave basin and exposed to scaled reproductions of the extreme waves and water levels expected at the site (Fig. 1-3). Most tests were conducted with 3-hour realizations of irregular waves synthesized from JONSWAP spectra, although tests with regular waves were also performed. Test conditions were selected to simulate extreme seastates spanning return periods of approximately 50 to 2,000 years. Different wave headings were simulated by rotating the model structure within the wave basin.

The deck model consisted of a solid deck slab supported on a welded grid of longitudinal and transverse aluminum beams, all with rectangular cross-section (Fig. 2). The joints between the beams and the solid deck were sealed to prevent air and/or water from escaping. The deck was supported on a rigid assembly of 25 circular steel piles and 16 pile caps. The elevation of the pile assemblies and the pier deck could be varied in discrete increments by inserting spacer blocks below the base of each pile. Deck elevations from $+13.9 \mathrm{~m}$ to $+18.5 \mathrm{~m}$ were modelled.

The local pressures on the surface of the model were measured in 26 locations using $19 \mathrm{~mm}$ stainless steel pressure sensors suitable for measuring impulsive pressure fluctuations with rapid rise times. The forces and moments acting on portions of the pier deck were measured in three locations. At each location, sections of the pier deck were isolated from the surrounding deck structure and suspended from a 6-axis load cell mounted on a rigid beam located above the deck.

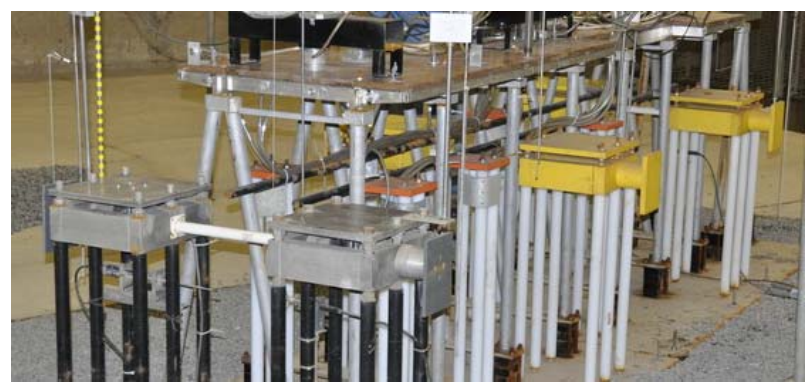

Figure 1 - 1/35 scale model of deck-on-pile wharf structure

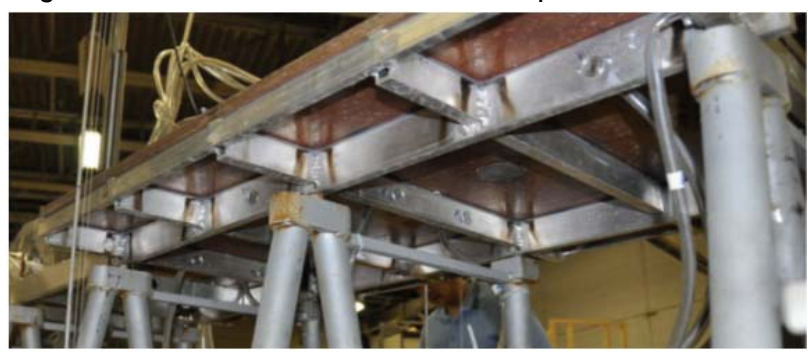

Figure 2 - Underside of the model deck

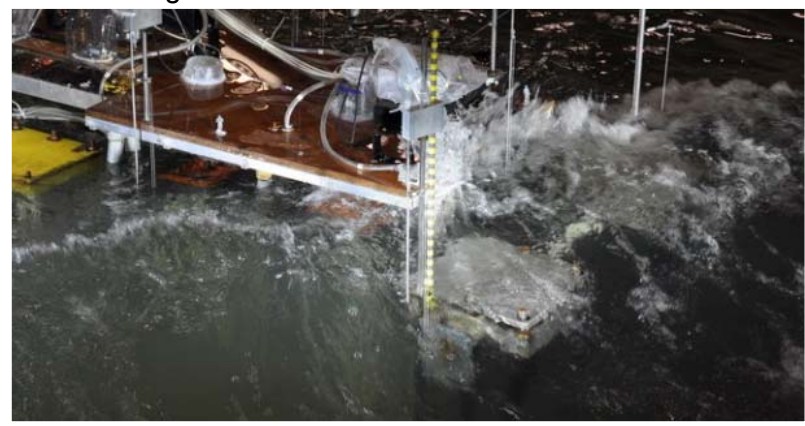

Figure 3 - Wave crest interacting with the model wharf. 


\section{INFLUENCE OF DECK CLEARANCE}

Results from nearly 400 tests have been analyzed to reveal the important influences of air gap and wave heading on extreme pressures and deck loads. Fig. 4 shows three examples of the relationships between wave-in-deck load and deck clearance (air gap) developed from this dataset. These figures show the maximum dimensionless force $\left(\mathrm{F}^{*}\right)$ recorded on an exposed portion of the deck during 3-hours of irregular wave attack as a function of dimensionless deck clearance $\left(C^{*}\right)$. The design curves shown in these figures can be written in the form

$$
\mathrm{C}_{\min }^{*}=\mathrm{a}-\left(\mathrm{F}^{*}\right)^{\mathrm{b}} \mathrm{C}_{\min }^{*}=\mathrm{a}-\left(\mathrm{F}^{*}\right)^{\mathrm{b}}
$$

The coefficients $a$ and $b$ that provide a good fit to the data are given in Table 1 .

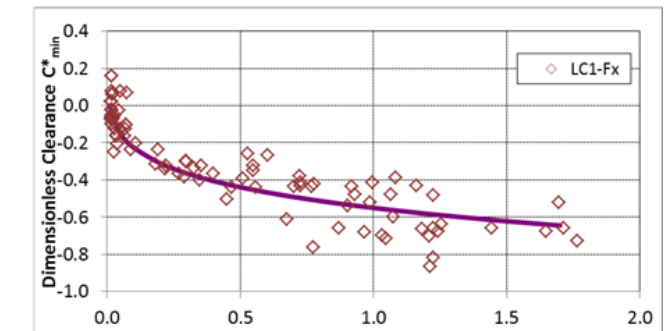

a) Dimensionless Maximum Horizontal Force $\mathrm{Fx}^{*}$

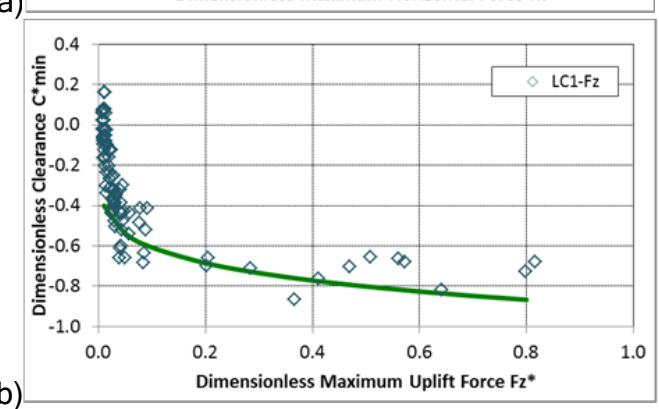

b)

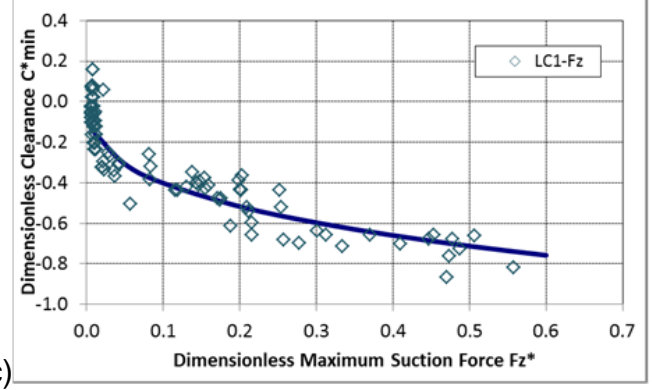

Figure 4 - Influence of air gap on peak wave-in-deck loads.

Table 1 - Value of coefficients $a$ and $b$ in equation 1

\begin{tabular}{lcc}
\hline Force component & $\mathrm{a}$ & $\mathrm{b}$ \\
\hline $\mathrm{F}_{\mathrm{x}}{ }^{*}$ (horizontal) & 0.45 & 0.17 \\
\hline $\mathrm{F}_{\mathrm{z}}{ }^{*}$ uplift & 0.10 & 0.15 \\
\hline $\mathrm{F}_{\mathrm{z}}{ }^{*}$ suction & 0.10 & 0.30 \\
\hline
\end{tabular}

\section{CONCLUSIONS}

An extensive set of laboratory experiments has been conducted to investigate the pressures and loads exerted by steep shallow-water waves on portions of a large deck-on-pile structure. The presentation and full paper will present new experimental data and provide new insights into the character and magnitude of the hydrodynamic pressures and loads exerted on pilesupported deck structures by steep shallow-water waves, with a focus on the important influences of deck clearance (air gap) and wave heading.

\section{REFERENCES}

Baarholm, Faltinsen (2004): Wave impacts underneath horizontal decks. J. Mar Sci Tech 9:1-13

Baarholm, Stansberg (2004): Extreme vertical wave impact on the deck of a gravity-based structure (GBS) platform. Proc. Conf. on Rogue Waves.

Baarholm (2009): Experimental and theoretical study of 3-D effects on vertical wave-in-deck forces. Proc. 2009 OMAE Conf., paper 79560, Honolulu, USA.

Bea, Xu, Stear, Ramos (1999): Wave forces on decks of offshore platforms. J. Waterway, Port, Coastal and Ocean Eng. 124-3 136-144.

Bea, Iversen, Xu (2001): Wave-in-deck forces on offshore platforms. J. Offshore Mechanics and Arctic Eng. 123 10-21.

Chen (2010): Time domain simulation of nonlinear wave impact loads on fixed offshore platform and decks. Proc. $20^{\text {th }}$ ISOPE Conf., pp 364-371.

Cuomo, Tirindelli, Allsop (2007): Wave-in-deck loads on exposed jetties. J. Coastal Eng. 54 657-679.

Cuomo, Shimosako, Takahashi (2009): Wave-in-deck loads on coastal bridges and the role of air. J. Coastal Eng. 56 (2009) 793-809.

Finnigan, Petrauskas (1997): Wave-in-deck forces. Proc. $6^{\text {th }}$ ISOPE Conf., Honolulu, USA.

Kendon, Pakozdi, Baarholm, Berthelsen, Stansberg, Enger (2010): Wave-in-deck impact: comparing CFD, simple methods, and model tests. Proc. 2010 OMAE Conf., paper 20860, Shanghai, China.

Lande, Johannesen (2011): CFD Analysis of Deck Impact in Irregular Waves. Proc. 2011 OMAE Conf., paper 49418, Rotterdam, the Netherlands.

Meng, Chen, Yan (2010): Wave interaction with deck of jetty on a slope. Proc. 2010 Int. Conf. on Coastal Eng., Beijing, China.

Murali, Sundar, Setti (2009): Wave-induced pressures and forces on deck slabs near the free surface. $J$. Waterway, Port, Coastal and Ocean Eng. 135:269-277.

Murray, Winsor (1997) Impact forces on a jacket deck in regular waves and irregular wave groups. Proc. 1997 Offshore Tech. Conf., paper 8360, Houston, USA.

Raaij, Gudmestad (2007): Wave-in-deck loading on fixed steel jacket decks. J. Marine Structures 20, 164-184.

Schellin, Peric, Moctar (2009): Wave-deck-load analysis for a jack-up platform. Proc. 2009 OMAE Conf., paper 79633, Honolulu, USA.

Tirindelli, Cuomo, Allsop, Lamberti (2003): Wave-in-deck forces on jetties and related structures. Proc. $13^{\text {th }}$ ISOPE Conf., pp 562-569.

Wemmenhove, Lefranc (2011): CFD Calculations of Wave-in-Deck Load on a Jacket Platform - Impact Pressure Decrease due to Air Pocket Formation. Proc. 2011 OMAE Conf., paper 49515. Rotterdam, Netherlands. 